\title{
The Contribution of Homeroom Teachers' Attachment Styles and of Students' Maternal Attachment to the Explanation of Attachment-like Relationships between Teachers and Students with Disabilities
}

\author{
David Granot* \\ Department of special education, Oranim-Academic College of Education, Tivon, Israel \\ *Corresponding author: dudi_g@oranim.ac.il
}

Received August 09, 2014; Revised August 23, 2014; Accepted August 29, 2014

\begin{abstract}
Over the past 25 years, numerous studies have sought to explore the ways in which the quality of teacher-student relationship develops. Such relationships are considered particularly significant in the case of students diagnosed with learning disabilities (LD) and attention deficit hyperactivity disorder (ADHD). The study involved 65 dyads of Israeli homeroom teachers and their students (mean age $=10.9$ ) with disabilities (LD, ADHD, and LD/ADHD comorbidity) in regular educational settings, receiving special assistance from "integration teachers." The study examined the effect of student-teacher attachment features on day-to-day student-teacher "attachmentlike” relationships. Students reported on their felt security with their mother using a maternal attachment security scale. Appraisal of the teacher as a secure base was conducted using availability/acceptance and rejection scales. Teachers completed the attachment style (secure, avoidant, and ambivalent) questionnaire and the teacher-student relationship scale concerning emotional closeness, conflict, and student dependency. Findings show that elementary and junior high school teachers and their students develop relational perceptions of secure and insecure attachmentlike relationships. The teachers' caregiver perception of the relationship was explained strictly by the students' reports of day-to-day security in the teacher-student relationship. Student care receiver perception of the actual teacher-student relationship was explained with greater sensitivity by maternal attachment security, teacher attachment style, and teacher-reported day-to-day security in the teacher-student relationship. Finally, the teachers' attachment level of security was found to moderate the association between student maternal attachment security and the students' appraisal of teacher as a secure base. Students of teachers with a mid-to-high level of attachment security exhibited a positive association, whereas students of teachers with mid-to-low level of attachment security exhibited no association. Implications for teacher education and research are discussed.
\end{abstract}

Keywords: teacher-student attachment-like relationships, children with disabilities, elementary and junior high school students

Cite This Article: David Granot, "The Contribution of Homeroom Teachers' Attachment Styles and of Students' Maternal Attachment to the Explanation of Attachment-like Relationships between Teachers and Students with Disabilities." American Journal of Educational Research, vol. 2, no. 9 (2014): 764-774. doi: 10.12691/education-2-9-10.

\section{Introduction}

There is growing understanding of the interactive character of children's individual socio-emotional development within their social context as a whole, and specifically of the importance of the substantial amount of interaction they experience with their teachers in school (Murray \& Greenberg, 2006). The research on quality of the teacher-student relationship has been guided primarily by three broad themes or perspectives: attachment, motivation, and sociocultural perspective (Davis, 2003; Pianta, 1999). According to the first approach, teachers serve as alternative caregivers who provide a "secure base" from which children can explore and adjust to the socio-emotional environment of the school based on the teachers' accessibility and sensitivity to student needs (Zionts, 2005). "Good" teacher-student relationships enable students to regulate their emotional and social behavior and conform to school learning demands (Pianta, 1999). Using the attachment approach, we seek to evaluate the teacher-student relationship based on features associated with parent-child attachment relationships, such as availability, acceptance, emotional closeness, rejection, conflict, and dependency (Bergin \& Bergin, 2009; Davis, 2003). The present research takes into account the Israeli homeroom teacher's special function as the student's de facto primary school caregiver, and thus it relies on the attachment perspective and the features listed above. 
In the past 25 years many studies have explored the influence of the teacher-student relationship quality on the adequate development of typically developing students (Murray \& Greenberg, 2006; Murray \& Pianta, 2007; AlYagon \& Margalit, 2006). At the same time, few studies investigated the role of teacher-student relationships among schoolchildren with disabilities (Al-Yagon \& Margalit, 2006). The few existing studies on close relationships with teachers of children with disabilities, and the considerable amount of studies on close relationships with parents among children with disabilities revealed the role of these relationships as a protective factor for the children's social and emotional adaptive functioning (Al-Yagon, 2009; Arthur, 2003). Therefore, positive relationships with teachers are particularly significant for the school adaptation of such students (Murray \& Pianta, 2007). Sabol and Pianta (2012) suggested that for children at risk, together with the quality of the parent-child relationship, the quality of the teacher-child relationship is no less important, because it can serve as a distinct and significant protecting factor in their lives and buffer inadequate school adjustment. The findings of Buyse, Verschueren, and Doumen (2011) support this idea and show that teacher caregiving qualities can transform the mental representation that children have developed about their relationships with their parents. Most of the existing studies indicate that, compared to teacher-students relationships of typically developing students, those of students with disabilities are characterized by a higher level of rejection and dissatisfaction, and lover levels of acceptance, closeness. Moreover, teachers in general have difficulty establishing optimal relationships with students with disabilities (AlYagon \& Mikulincer, 2004). At the same time, according to Myers and Pianta (2008), at times teacher-problematic student dyads can and do form constructive relationships. Furthermore, Hughes (2012) emphasized that the quality of teacher-student relationships is determined not only by what the child contributes to the relationship but also by what the teacher brings to the day-to-day interactions. Sabol and Pianta (2012) suggested that examination of the degree to which high-quality teacher-student relations affect at-risk students can expand existing knowledge about whether relationships with teachers can correct developmental processes for the most susceptible children. Following this suggestion, the present study explores the attachment-like relationships between Israeli homeroom teachers and students with disabilities (LD, ADHD, and $\mathrm{LD} / \mathrm{ADHD}$ ) who receive special assistance from "integration teachers" during school hours. The majority of previous studies focusing on teacher-student's relationships tend to address almost exclusively student attachment characteristics. By contrast, the distinctiveness of the present study lies in the fact that it addresses also the attachment styles of the teachers and their association with the students' representations of close interpersonal relationships.

\subsection{Prior Attachment and Teacher-student Relationships}

According to attachment theory, during early (preverbal) childhood children develop internal working models (IWM) within the parent-child relationship. These include representations of others as trustworthy, as well as of selfworth and self-effectiveness when interacting with others. These mental representations, which were shaped by early attachment figures, later guide relations with other primary relationships partners (i.e., teachers; Buyes et al., 2011). Many researchers have argued that the relationships students develop with teachers are analogous to their original mother-child attachment relationship (AlYagon \& Mikulincer, 2006). Numerous studies have shown that students' attachment relationships with their teachers corresponded to their relationship with their primary caregivers (Cotterell, 1992; Pianta, 1999; Pianta, Nimetz, \& Bennett, 1997). At the same time, others have indicated that despite this correlation, teachers and children alike may develop alternative types of relationships (Howes \& Hamilton, 1992; Lynch \& Cicchetti, 1997). According to this view, the quality of the teacher-student relationship is not determined strictly by the student's early childhood attachment-relationship but also reflects the day-to-day bidirectional interactions within the teacher-student dyad (reciprocal pair relation) relationship (Oppenheim, Sagi, \& Lamb, 1988).

The present study seeks to contribute to this discussion by making two suggestions. First, that teacher-student relationship is also affected by the status of each of the two partners in the dyad. On the teacher's side, the perception of the relationship is associated primarily with the student's actual appraisal of day-to-day interactions with the teacher as a caregiver, guided by the pedagogic awareness. On the side of the student, as a care recipient, the perception of the relationship is associated jointly with the student's maternal attachment security, the homeroom teacher's attachment characteristics, and the teacher's perception of day-to-day relationships with the student. Second, consistent with Buyes et al., (2011) we found that teacher caregiving features can modify the children's internal working models of their attachment relationships with their parents. We suggest that the teacher's attachment characteristics can moderate the associations between the children's maternal attachment and their appraisal of their teacher as a secure-base for them.

\subsection{Purpose of the Present Study}

The present study included 65 dyads comprised of Israeli homeroom teachers and their regular public school students with disabilities (LD, ADHD, and LD/ADHD), receiving special assistance from "integration teachers" during school hours. According to the Policy Circular of the Israeli Ministry of Education (1994), homeroom teachers hold their position for a minimum of two and a maximum of three years. Homeroom teachers fulfill three central roles: (a) student case manager, (b) school intermediary on behalf of parents, subject teachers, educational counselors, special education "integration teachers," the school psychologist, the principal etc., and (c) primary educational contact for students. Thus, the homeroom teacher is the student's main school address for dealing with personal issues, and serves as the de facto school caregiver figure.

Conforming to Israeli educational policy regarding the integration of children with special needs in the school (Alon-Reshef, 1994), 95\% of children diagnosed with LD and ADHD study in regular public schools (Statistical 
Yearbook of Israel, 2012) and constitute approximately $10 \%$ of students in each classroom in Israel (Al-Yagon \& Mikulincer, 2006). According to Israeli educational policy, after a homeroom teacher evaluates a child with disabilities as showing close-to-typical development, average academic functioning, and no significant social, behavioral, or emotional problems, the child can stay in the a regular classroom and is eligible to receive special assistance from a special education "integration teacher" (Al-Yagon \& Mikulincer, 2006). Work with the integration teacher includes two to three hours per week of individual remedial teaching in a small, special education group of up to five students, and general instruction to improve reading comprehension, written expression, and math proficiency skills.

Our preliminary goal was to explore the extent to which the student-teacher dyadic relationship of students with disabilities corresponds to their primary attachment relationship. To this end, we devised two measures: student-mother attachment security and teacher's attachment style (secure, avoidant, or ambivalent). Our first objective was to explore the contribution of joint student and teacher attachment characteristics to the explanation of teachers' and students' perceptions and beliefs about their day-to-day attachment-like relationship. To accomplish this, we devised two additional measures: students' appraisal of their homeroom teacher's availability-responsiveness or rejection, and the homeroom teacher's perception of emotional closeness, conflict, and dependency in the teacher's relationships with the student. According to Hughes (2012), "the quality of teacher-student relationships depends not only on what the child brings to the relationships, in terms of mental representations of relationships with caregivers and interpersonal competencies, but also on what the teacher brings to the relationships" (Hughes, 2012, p. 320). Based on this insight, our second objective was to explore the teachers' overall attachment security as a moderating factor between the students' maternal security and their appraisal of the homeroom teacher as a secure base figure.

Finally, studies of teacher-student relationships suggest that the teachers' perception of their relationships with students may be influenced by the students' demographic and biological attributes such as age, gender, socioeconomic and family background, and difficult life events (Birch \& Ladd, 1997; Hughes, Gleason, \& Zhang, 2005; Kesner, 2000; Murray \& Pianta, 2007; Saft \& Pianta, 2001). Therefore we controlled statistically for the effect of these student variables.

\section{Hypotheses}

H1: The students' appraisal alone of their day-to-day perception of the homeroom teacher as a secure base figure explains the variance in the teachers' perceptions of the attachment-like relationships with their students, beyond factors relating to student demographic and biological attributes (age, gender, learning disabilities, etc.).

H2: Both student and teacher attachment characteristics, and the teacher's perceptions of actual day-to-day attachment-like relationship with the student explains the variance in the students' appraisal of the homeroom teacher as a secure base figure, beyond student demographic and biological attributes (age, gender, learning disabilities, etc.).

H3: The teacher's attachment security moderates the association between student's maternal attachment security and the student's appraisal of the homeroom teacher as a secure base figure.

Specifically, we hypothesized that students of teachers with mid-to-high level of attachment security exhibit a positive association, whereas students of teachers with mid-to-low level of attachment security exhibit no association.

\section{Method}

\subsection{Participants}

The sample was composed of 65 homeroom teacherstudent with disabilities dyads, of whom 25 were students with LD (13 boys, 12 girls), 20 with ADHD (10 boys, 10 girls), and 20 with comorbidity (LD/ADHD) (10 boys, 10 girls). The teacher sample consisted of 65 experienced ( 3 or more years of teaching experience), graduate-level, female homeroom teachers: 17 grade 3 teachers, 9 grade 4 teachers, 13 grade 5 teachers, 8 grade 6 teachers, 7 grade 7 teachers, and 11 grade 8 teachers. The student sample (49.25\% males and 50.8\% females) was composed of $46 \%$ 8-10 years old (middle childhood) students and 54\% 1114 years old (early adolescent) students. Participating students received special assistance from "integration teachers" in their regular public schools, in a middle-tolow-class area in northern Israel. Parental permission was obtained for participation (95\% compliance rate), and confidentiality was guaranteed to all the participants.

\subsection{Student Characteristics}

LD and ADHD students in regular public schools receive special assistance from special education integration teachers. Consistent with Israeli Ministry of Education policy, they must have an average IQ level. All the diagnostic data obtained from the schools remain anonymous to observe the requirements of confidentiality

\section{LD group}

The children must have a psycho-educational evaluation that diagnoses them as suffering from learning disabilities in reading, writing, and/or mathematics. According to Ministry policy, the LD diagnosis is based on DSM 4th ed. (American Psychiatric Association, 2000) discrepancy criteria. The assessment was conducted by a psycho-educational team at the school or by private psycho-educational professionals, using neuropsychological instruments such as the Wechsler Intelligence Scale for Children-3rd Edition (Wechsler, 1991), the BenderGestalt Test (Koppitz, 1975), the Rey-Osterrieth Complex Figure Test (Osterrieth, 1946), the Hebrew version of the Rey Auditory Verbal Learning Test (Vakil \& Blachstein, 1993), and reading, writing, and math psycho-didactic diagnostic assessments (conducted in Hebrew).

\section{ADHD group}

The students' ADHD diagnosis is based on a comprehensive clinical diagnostic assessment by pediatricians or psychiatrists/neurologists specializing in 
attention disorders. The assessments revealed scores in the deficit range of the Continuous Performance Test (Conners, 1996) and of standardized clinical assessments in interview sessions using DSM 4th ed. (2000) criteria. All participants exhibited a persistent pattern of inattention and/or hyperactivity-impulsivity, and received medication (e.g., methylphenidate). All the diagnostic data obtained from the schools remain anonymous to observe the requirements of confidentiality.

\section{Comorbidity group}

The LD and ADHD symptoms of these children were determined as described above.

\subsection{Procedure}

\subsubsection{Sample Pool}

To focus on the relationships between homeroom teachers and students receiving assistance from special education integration teachers in regular classrooms, the sample was comprised of 65 separate homeroom teacherstudent dyads, involving 65 homeroom teachers (with 2533 students per class), from 61 public schools.

Data were collected by different interviewers in the middle of the second trimester of the school year. The research team consisted of BA graduates in Special Education performing their internship in the participating schools. The interviewers were asked to recruit experienced homeroom teachers and identify students diagnosed as suffering from LD, ADHD, or LD/ADHD. To ensure that the dyad had an established relationship, only students who were at least in their second year with the homeroom teacher were included. The academic achievements of the students (according to school records) were within the average range of students receiving assistance from special education integration teachers. After obtaining school and parental permission for the students' participation, the interviewers met with each child and homeroom teacher individually. The meetings took place at school but outside the classroom to ensure that students felt as comfortable as possible answering questions about their relationship with their homeroom teacher. The researcher read out loud sample items from each questionnaire to confirm that the students understood the items, and provided help when necessary. After the research instruments had been introduced, each child was asked to demonstrate reading-comprehension competence before completing the Attachment Security Scale (ASS; Kerns, Klepac, \& Cole, 1996), the Children's Appraisal of Teacher as a Secure Base Scale (CATSBS; Al-Yagon \& Mikulincer, 2006), and the Children's SocioeconomicFamilial Background Indicators Questionnaire (Yair, 1991). All the students were told that their responses to all the questions were confidential and would not be shared with anyone at school. The teachers were then asked to complete the Attachment Style Questionnaire (ASQ; Mikulincer \& Erev, 1991) and the Student-Teacher Relationships Scale (STRS; Pianta \& Steinberg, 1992). Finally, the student reports regarding their socioeconomic/family background were validated against school records regarding the SES status of their families.

\subsubsection{Student Socio-Economic/Family Background} Indicators
According to Yair (1991), the principal indicators of higher-level socio-economic status in Israel include wages (by occupation), a low ratio of people to rooms, and the number of difficult life events. Participating students' reports of their parents' occupations (unemployed, housewife, salesperson, teacher, engineer, hi-tech worker, medical doctor, etc.) were classified into the following categories: (a) minimum or no wage (21\% mothers, $17 \%$ fathers); (b) low wage (39\% mothers, 25\% fathers); (c) average wage (31\% mothers, $40 \%$ fathers); (d) high wage ( $9 \%$ mothers, $17 \%$ fathers); (e) very high wage $(0 \%$ mothers, $1 \%$ fathers). The child's family earning level was calculated by combining the parents' wage level scores. Results range from 2 to 8 (45\% [2-4], 34\% [5-6], and 22\% [7-8]). Based on reports of the ratio of people to rooms, $43 \%$ of the participants had less than one room per person, $32 \%$ one room per person, and 25\% more than one room (maximum 2) per person. The difficult life-event indicator was calculated by totaling the participants' reports about death in the family, parental divorce, single-parent families, serious illness or hospitalization in the family, immigration, bankruptcy, and parent-child relationship crisis. The score ranged from 0 to 2, with $59 \%$ experiencing no difficult life events, $28 \%$ one, and $14 \%$ two such events. An adequate correspondence was found between the participants' socio-economic/family background questionnaires and the school records relating to the SES of the families.

\subsection{Student and Homeroom Teacher Measures}

\subsubsection{Students' Attachment Security}

The student attachment security level was measured by the Attachment Security Scale (ASS; Kerns, Klepac, \& Cole, 1996). This is a self-report questionnaire designed to assess the students' perceived security in their early mother-child attachment relationship. Items on the ASS address the degree to which children believe a particular attachment figure is responsive and available, their reliance on her in times of stress, and their reported ease and interest in communicating with her. The measure is composed of 15 items rated on a 4-point scale based on Harter's (1982) “Some kids... Other kids...” format. Children read statements such as "Some kids find it easy to trust their mom BUT other kids are not sure if they can trust their mom," and are asked to indicate which statement characterizes them better, indicating whether the statement is entirely or partially true for them. Scores are totaled and averaged across the 15 items to form an Attachment Security Score between 1 and 4, the higher scores denoting more secure relationships. The ASS results obtained in the present study exhibited high internal consistency $(\alpha=.80)$.

\subsubsection{Homeroom Teacher's Attachment Styles}

The attachment style of the homeroom teachers was assessed using the Attachment Style Questionnaire (ASQ; Mikulincer \& Erev, 1991). This is a 15-item self-report questionnaire based on Hazan and Shaver's (1987) three descriptions of feelings and cognitions corresponding to the three adult attachment styles (secure, avoidant, and ambivalent). Hazan and Shaver (1987) claimed that a 
single description of each attachment style is inadequate for classifying it, and Mikulincer and Erev (1991) separated the items and developed a 15-statement scale (five items per style). The Attachment Style Questionnaire seeks endorsement of each of the three attachment styles: secure ("I usually believe that others who are close to me will not leave me"), avoidance ("Sometime others get too close and too intimate with me"), and ambivalence ("I'm sometimes afraid that others don't really love me”). The questionnaire used in the present study was Mikulincer and Erev's (1991) Hebrew translation of Hazan and Shaver (1987). The homeroom teachers were asked to rate the extent to which each item describes their feelings in their relationships with others on a 7-point scale $(1=$ Not at all appropriate; 2 = Not appropriate; 3 = Slightly not appropriate; 4 = Partly appropriate and partly not appropriate; 5 = Partly appropriate; $6=$ Appropriate; $7=$ Very appropriate). Three scores were computed by averaging all the items corresponding to each attachmentstyle subscale, higher scores reflecting greater endorsement of each style. Cronbach $\alpha$ internal consistency reliabilities for the three attachments factors were acceptable (between 5.8 and 6.35), consistent with earlier investigations (Mikulincer \& Orbach, 1995).

\subsubsection{Students’ Perceived Teacher-Student Relationship}

The students' appraisal of their teacher as an attachment figure was assessed using the Children's Appraisal of Teacher as a Secure Base Scale (CATSBS; Al-Yagon \& Mikulincer, 2006). This is a 25-item self-report questionnaire relating to various attachment facets. The items on this scale were used to evaluate the students' perceptions of their homeroom teacher as a secure base from both a positive (availability, acceptance) and a negative (rejection) perspective. The availability and acceptance subscale comprises 17 items that address the extent to which the child perceives the homeroom teacher as available in time of need ("My teacher is always there to help me when I need her") and as a caring figure who accepts the student's needs, feelings, and behaviors ("The teacher makes me feel welcome in the class"). The rejection subscale comprises 8 items that explore the degree to which the child perceives the teacher as rejecting ("My teacher makes me feel unwanted"). Children were asked to rate the extent to which each item describes their homeroom teacher on a 7-point scale $(1=$ Does not apply at all; $7=$ Applies very much). Two scores were computed by averaging items corresponding to each appraisal scale (positive and negative), higher scores reflecting appraisal of the teacher as an available/accepting secure base figure. The CATSB scale results in the present study exhibited high Cronbach alpha internal consistency coefficients (availability/acceptance $=.96$; rejection $=.87$ ).

\subsubsection{Teacher Perceptions of the Relationship}

The homeroom teachers' perceptions of the teacherstudent relationship was measured by the Student-Teacher Relationships Scale (STRS; Pianta \& Steinberg, 1992), a 28-item self-report measure designed to assess teachers' perceptions of their relationship with a particular student based on three dimensions (conflict, closeness, and dependency). The scale, which has been employed to classify parent-child attachment relationships (Davis,
2003), focuses on the relation between the students' perceived security with a teacher and their tendency to explore the school environment (Hamre \& Pianta, 2001). The 12-item conflict subscale addresses the negativity and lack of empathy between teacher and student, e.g., "This child and I always seem to be struggling with each other." The closeness subscale comprises 11 items that address the extent of warmth, positive affection, and open communication between teacher and student, e.g., "I share an affectionate, warm relationship with this child.” The dependency subscale comprises 5 items about the degree to which the student exhibits clinginess or an overpossessive attitude toward the teacher, e.g., "This child is overly dependent on me." The answers are provided on a 5-point scale $(1=$ Definitely does not apply; $5=$ Definitely applies). Three scores are computed by averaging the items corresponding to each relationship scale, higher scores indicating greater conflict, closeness, and dependency. The internal consistency reliabilities for the current sample were as follows: conflict: $\alpha=.89$, closeness: $\alpha=.86$, and dependency: $\alpha=.63$. These reliabilities are consistent with earlier investigations (Pianta, 1996; Murray \& Murray, 2004).

\section{Results}

\subsection{Preliminary Analyses}

Preliminary analyses were conducted to assess whether the two principal groups of variables in the study, (a) teachers' and the students' attachment characteristics, and (b) teachers' and students' perceptions and beliefs regarding their actual attachment-like relationship, were related to the students' demographic variables (gender, age, socio-economic/family level, difficult life events, and diagnosed school-related disabilities).

\subsubsection{The Relations between Teacher and Student Attachment Characteristic, and Perceptions of Teacher-student Attachment-like Relationship and Student Demographic Background Variables}

To examine potential demographic differences within the measures, a series of t-test analyses was conducted. The tests assessed whether boys and girls differed with regard to maternal attachment security, appraisal of the teacher as a secure base, and homeroom teachers' reports regarding the teacher-student relationship and teacher's attachment style. None of the results were statistically significant. Pearson correlations between the teacher/student self-report measures and student age revealed a single significant negative association with teacher reports regarding close relationships with their students $(r=-.31, \mathrm{p}<.001)$. These results are consistent with previous findings, suggesting that the quality of the teacher-student relationship frequently deteriorates following the transition from childhood into middle childhood and early adolescence (National Research Council, 2004). Therefore, in the subsequent analysis we statistically controlled for student age through teacher reports on the closeness sub-scale. Similarly, a series of ttest analyses was conducted to assess whether differences existed between the middle-childhood $(\mathrm{N}=30)$ and earlyadolescent $(\mathrm{N}=35)$ student groups with respect to maternal 
attachment security, appraisal of teacher as a secure base, and the homeroom teacher's reports regarding the teacherstudent relationships. None of the results were statistically significant. Pearson correlations between teacher and student attachment characteristics, perceptions of the teacher-student attachment-like relationship, and student socio-economic background indices (family earning level, room-per-person ratio), and difficult life events proved non-significant. A series of one-way ANOVAS was conducted in which the three disabilities groups (LD, ADHD, and of LD/ADHD comorbidity) were used as the criterion variable, and teacher/student attachment characteristics and perceptions of the teacher-student attachment-like relationship sub-scales (9) served as the predictor variables. None of differences were statistically significant.

\subsection{The Role of Teacher/student Attachment Styles in Explaining Teacher-student Attachment-like Relationships}

Before examining the role of teacher/student attachment characteristics in explaining teacher-student attachmentlike relationship, we analyzed the association between the various teacher and student attachment-based variables.

\begin{tabular}{|c|c|c|c|c|c|c|c|c|c|c|c|c|c|}
\hline & Variable & Range & Mean & SD & 1 & 2 & 3 & 4 & 5 & 6 & 7 & 8 & 9 \\
\hline 1 & Child ASS & $1.6-4.0$ & 3.10 & 0.5 & - & & & & & & & & \\
\hline 3 & Teacher avoidant ASQ & $1.2-5.0$ & 2.92 & 0.8 & -.06 & $-.46^{* *}$ & - & & & & & & \\
\hline 4 & Teacher ambivalent ASQ & $1.0-5.2$ & 2.58 & 0.9 & -.04 & -.18 & $-.35^{* *}$ & - & & & & & \\
\hline 6 & Student CATSB rejection & $1.0-5.9$ & 2.00 & 1.2 & $-0.43^{* *}$ & $-0.27 *$ & $0.29 *$ & $0.41 * *$ & $-0.83^{* *}$ & - & & & \\
\hline 7 & Teacher STRS closeness & $1.7-4.7$ & 3.32 & 0.7 & $0.40 * *$ & 0.17 & -0.04 & $-0.30 *$ & $0.59 * *$ & $-0.51 * *$ & - & & \\
\hline 8 & Teacher STRS conflict & $1.0-3.9$ & 1.86 & 0.7 & $-0.34 * *$ & $-0.23^{*}$ & $0.28 *$ & $0.30 *$ & $-0.41^{* *}$ & $0.43^{* *}$ & $-0.46^{* *}$ & - & \\
\hline 9 & Teacher STRS dependency & $1.0-4.0$ & 1.92 & 0.7 & 0.01 & -0.19 & $0.29 *$ & 0.13 & -0.01 & 0.11 & 0.09 & $0.44^{* *}$ & - \\
\hline
\end{tabular}

As shown in Table 1, student's perceived security in maternal attachment was positively associated with appraisal of the teacher as an available and accepting figure, and with teacher perception of closeness in the relationship, and negatively associated with student appraisal of the teacher as rejecting figure and with teacher's perception of the conflictual nature of the relationships. Secure teacher attachment style was positively associated with student appraisal of the teacher as an available and accepting figure, and negatively associated with student appraisal of the teacher as a rejecting figure and with teacher perception of the conflictual nature of the relationship. Insecure teacher attachment styles (avoidant, ambivalent) were negatively associated with student appraisal of the teacher as an available-accepting figure, and with teacher perception of closeness in the relationship, and positively associated with student appraisal of the teacher as a rejecting figure, and with teacher perception of the conflictual and dependent nature of the relationship. Similarly, student appraisal of the teacher's availability and acceptance was positively associated with teacher perceptions of closeness in the relationships and negatively associated with teacher perceptions of the conflictual nature of the relationship, whereas student appraisal of teacher rejection was positively associated with teacher perception of the conflictual nature of the relationships and negatively associated with teacher perception of closeness in the relationship.

\subsubsection{The Extrapolation of Overall Continuous Secure Attachment and Attachment-like Indicators}

As shown in Table 1, significant - negative and positive strong-to-high Pearson correlations also emerged between some of the sub-scales of the measures that contained a number of scales (e.g., Attachment Styles Scale,
Children's Appraisal of Teacher as a Secure Base, Student-Teacher Relationships Scale), creating a risk of multi-colinearity in the regression analysis (Baron \& Kenny, 1986). We therefore extrapolated three overall continuous secure attachment and attachment-like indicators from these:

1. The Attachment Style Scale (Mikulincer \& Erev, 1991) avoidant and ambivalent-insecure sub-scale values (10 items) were reversed into the absence of avoidant and ambivalent styles endorsed by the teachers in order to create the overall teacher securestyle scale (15 items) (Cronbach's $\alpha=.73$ ).

2. The CATSB (Al-Yagon \& Mikulincer, 2006) rejection sub-scale values (8 items) were reversed into the absence of teacher rejection responses to student perception in order to create the overall student appraisal of the teacher-as-a-secure-figure scale (25 items) (Cronbach's $\alpha=.87$ ).

3. The STRS (Pianta \& Steinberg, 1992) conflict and dependency subscale values (17 items) were reversed into the absence of conflict and dependency in teacher perception of the teacher-student relationship in order to create the overall teacher report regarding security on the teacher-student relationship scale (28 items) (Cronbach's $\alpha=.90)$.

4.2.2. Contribution of the Various Attachment Features to Student and Teacher Perceptions and Beliefs Regarding Their Actual Attachment-like Relationships

We conducted two hierarchical regression analyses to assess the extent to which teacher/student attachment characteristics and reports regarding the actual relationship (each one separately) account for their counterpart's respective reports about their day-to-day attachment-like relationship (see Table 2 and Table 3), controlling for student age. 
Table 2. Hierarchal regression analyses of teacher overall reported security in teacher-student relationships, student maternal-attachment security, teacher overall secure style, student overall appraisal of teacher as a secure figure, and age as moderator variables

\begin{tabular}{|c|c|c|c|}
\hline & \multicolumn{3}{|c|}{ STRS-teacher overall reported security in teacher-student relationship } \\
\hline Predictor measures and step & $\beta$ & $\mathrm{R} 2$ & $\Delta R$ \\
\hline Step 1 & & 0.05 & 0.05 \\
\hline Student age & -.22 & & \\
\hline Step 2 & & $0.40 * * *$ & 0.40 \\
\hline Student age & -.19 & & \\
\hline ASS-student attachment security & 0.20 & & \\
\hline ASQ-teacher overall secure style & 0.19 & & \\
\hline CATSB-student overall appraisal of teacher as a secure figure & $0.36 * *$ & & \\
\hline
\end{tabular}

${ }^{*} \mathrm{p}<0.05 .{ }^{* *} \mathrm{p}<0.01 . * * * \mathrm{p}<.001$.

Total $\mathrm{F}(4,62)=9.55(\mathrm{p}<0.001)$.

Table 3. Hierarchal regression analyses of student overall appraisal of teacher as a secure figure, student maternal-attachment security, teacher overall secure style, teacher overall security in teacher-student relationships, interaction of student maternal-attachment security $x$ teacher overall security, and student age as moderator variables

\begin{tabular}{|c|c|c|c|}
\hline \multirow[b]{2}{*}{ Predictor measures and step } & \multicolumn{3}{|c|}{ CATSB-student overall appraisal of teacher as a secure figure } \\
\hline & $\beta$ & $\mathrm{R} 2$ & $\Delta R$ \\
\hline Step 1 & & 0.00 & 0.00 \\
\hline Student age & -.00 & & \\
\hline Step 2 & & $0.43^{* * *}$ & 0.43 \\
\hline Student age & 0.12 & & \\
\hline ASS-student attachment security & $0.24 *$ & & \\
\hline STRS-teacher overall reported security in teacher-student relationship & $0.35^{* *}$ & & \\
\hline \multicolumn{4}{|l|}{ Step 3} \\
\hline Interaction (ASS X ASQ) & $0.36 * *$ & $0.52 * *$ & 0.09 \\
\hline
\end{tabular}

${ }^{*} \mathrm{p}<0.05 .{ }^{* *} \mathrm{p}<0.01 .{ }^{* * *} \mathrm{p}<0.001$.

Total $\mathrm{F}(5,62)=12.20(\mathrm{p}<0.001)$.

As shown in Table 2, the student's age, which was introduced in the first step of the regression equation, did not contribute to the explanation of overall student appraisal of the teacher as a secure figure. Student/teacher attachment characteristics and overall student appraisal of the teacher as a secure figure were introduced in the second step of the regression equation. Only student appraisal of the teacher as a secure figure contributed significantly to the explanation of overall teacher-reported security in the teacher-student relationship (40\% additional explained variance). Higher student appraisal of the teacher as a secure figure was matched by higher overall teacher-reported security in the teacher-student relationship.

As shown in Table 3, student attachment characteristics, teacher attachment characteristics, and the teacher's perception of the teacher-student relationship, which were introduced in the second step of the regression equation, made a significant contribution to the explanation of the overall student appraisal of the teacher as a day-to-day secure figure (together they account for $43 \%$ of the explained variance). The more secure the students felt in their maternal attachment relationships, the higher was their overall appraisal of the teacher as a secure figure. Likewise, higher overall teacher secure attachment style contributed to higher student appraisal of the teacher as a secure figure. Finally, higher reported overall teacher security in the actual teacher-student relationship corresponded to higher overall student appraisal of the teacher as a secure figure. We entered the interaction between the student's maternal security and the teacher's overall secure style in the third and final step of the regression. The interaction (ASS $\times$ ASQ) contributes significantly to the explanation of the overall student appraisal of the teacher as a day-to-day secure figure ( $9 \%$ of the explained variance). Following Aitken and West's (1991) recommendation of the use of a cutoff point to compare two groups of participants in order to detect an interaction effect, we calculated based on the overall teacher secure attachment style a new categorical variable describing a mid-low level of security (ranging from 1= Not at all appropriate to $5=$ Partly appropriate, $n=28$ ) versus a mid-high level of security (ranging from $5.1=$ Above partly appropriate to $7=$ Very appropriate, $n=37$ ). Based on the new categorical variable, we found among the students of teachers with a mid-high level of security a positive significant high correlation between maternal attachment and appraisal of the teacher as a secure base ( $\mathrm{r}$ $=0.61, \mathrm{p}<0.01$ ), and among students of teachers with a mid-low level of security no significant correlation between maternal attachment and appraisal of the teacher as a secure base $(r=0.15, p=0.44)$. A Fisher R-to-Z transformation indicated a significant difference between the two correlation coefficients for the mid-high and midlow level of teacher security $(\mathrm{z}=-2.12, \mathrm{p}<0.05)$, indicating that students of teachers with a mid-high level of security benefited more than students of teachers with a mid-low level of security.

\section{Discussion}

The present study set out to investigate two aspects of dyad relationships between students with disabilities and teachers : (a) the extent to which student attachment security together with teacher attachment style contribute to the perception of students and teachers regarding the quality of their day-to-day relationship; and (b) the effect of teachers' attachment security as a moderator of the association between the student's maternal security and the 
student's appraisal of the homeroom teacher as a secure base figure.

We begin by reviewing the findings of the preliminary set of correlation analyses. As expected, controlling for student age, the Pearson correlation analysis demonstrated a significant association between student/teacher attachment characteristics and perceptions and beliefs about their attachment-like relationship. Higher student maternal attachment security was associated with higher closeness/ security levels and with lower conflictual/insecure levels in the student-teacher relationship as reported by teachers. Likewise, teacher secure attachment style was associated with higher student appraisal of the teacher as an available and responsive secure base figure and with lower student appraisal of the teachers as a rejecting secure base figure. Similarly, teacher insecure attachment styles (avoidant, ambivalent) were associated with lower levels of student appraisal of the teacher as an available and responsive secure base figure, and with higher levels of student appraisal of the teacher as a rejecting secure base figure (controlling for student age).

Teachers are likely to form close attachment-like relationships with early childhood or kindergarten students when they spend considerable time with them and are responsible for a range of their socio-emotional needs (Bergin \& Bergin, 2009). Many of the studies of teacher-student attachment-like relationships have been conducted in early childhood institutions rather than in elementary and junior high schools (Bergin \& Bergin, 2009). Our findings show that elementary and junior high school teachers and students also develop relational perceptions about secure and insecure attachment-like relationships. The degree of correspondence between student and teacher perceptions is remarkable considering that they were reporting on different aspects (teacher availability and acceptance or rejection on the part of student, and emotional closeness, conflict, or student dependency on the part of teachers). The study also demonstrates that the traditional aspects of parent-child attachment relationships are useful for the examination of the quality of middle-childhood/early adolescent teacherstudent relationships. It also suggests that parent-child and teacher-student share similar objectives: encouraging the exploration of the developmental agenda setting and developing social adaptive functioning with adults and peers in their developmental social environment. The moderate ( $r=0.41-0.59)$ correspondence between teacher and student reports regarding the quality of the relationship suggests that as students develop, both students and teachers view the student-teacher relationship differently. Because teacher (caregiver) and student (care receiver) reports serve different purposes, it is important that future studies assess both views. Our finding that elementary and junior high school teachers develop attachment-like relationships with their students with disabilities is especially important because previous studies emphasized the role of teacher-student relationships as a protective factor for the adjustment of children with disabilities in school (Al-Yagon, 2009; Murray \& Pianta, 2007).

Past studies have indicated that teachers' relationships with students with disabilities are expected to suffer from high levels of problematic interactions and a low level of confidence and proximity (Al-Yagon \& Mikulincer, 2004).
The sample of the present study, which included 65 students with disabilities (receiving services from integration teachers) randomly assembled from 65 classes in 61 schools, did not corroborate this finding. Indeed, student appraisal of teacher availability and responsiveness level $(\mathrm{M}=5.2, \mathrm{SD}=1.4)$ was significantly higher than student appraisal of teacher rejection level $(\mathrm{M}=2.0, \mathrm{SD}=1.2)$. Similarly, teacher-reported closeness in the relationship $(\mathrm{M}=3.3, \mathrm{SD}=0.7)$ was significantly higher than teacher-reported conflictual relationship $(\mathrm{M}=1.86$, $\mathrm{SD}=0.7)$ and then relations characterized by student dependency ( $\mathrm{M}=1.9, \mathrm{SD}=0.7)$.

The above results have several explanations. The first has to do with the fact that in Israel children diagnosed with LD and ADHD are eligible to receive assistance from special education integration teachers in regular classrooms when they are evaluated as exhibiting close-totypical development functioning and have no serious social, behavioral, or emotional problems. This makes it easier for teachers to deal with these children. Second, it is the integration teacher's responsibility to coordinate with the homeroom teacher the remedial teaching strategy and behavioral modification intervention for each child with disabilities in the homeroom teacher's care, to help create positive relationships between them. Moreover, whereas in most educational systems the children usually receive a different homeroom teacher every school year (Schuengel, 2012; Verschueren \& Koomen, 2012), in the present study the sample of homeroom teachers served as the students' primary school caregiver for at least two years, having a better chance of establishing a significant and close relationship with students. Finally, there are indications that students at risk can and do form sufficiently good relationships with teachers (Myers \& Pianta, 2008).

No significant associations were found between student attachment security, appraisal of the teacher as a secure/insecure base figure, and homeroom teacher reports regarding dependency. This finding can be explained by the specific cultural milieu in Israel, which is marked by a collectivistic orientation and a strong sense of involvement (Salomon \& Mayseless, 2003). In such a context, student dependency may be more acceptable and considered less maladaptive by both students and teachers than is the case in more individualistic cultures. Specifically, in a collectivist environment dependency associated with neediness may be tolerated in school if the teacher's orientation is caring and accepting. If this interpretation is correct, we can expect dependency to be better tolerated than conflictual behavior, attesting to a weaker relation with the teacher-student relationship.

\subsection{Contribution of Student/homeroom Teacher Personal Attachment Features to the Explanation of Their Attachment-like Relationship}

As hypothesized, the first hierarchical regression analysis indicated that student attachment security and overall secure teacher attachment style had no effect on overall teacher-reported security in the teacher-student relationship. In the second step of the regression equation, we introduced the overall student appraisal of the teacher as a day-to-day secure figure, which alone added a significant percentage (40\%) to the explained variance of 
overall teacher-reported security in the teacher-student relationship. These findings suggest that the teacher's perception of the teacher-student relationship is affected primarily by the bidirectional day-to-day interactions within the dyad. Possibly, in contrast with students in the present study, who are predisposed to relating to teacherstudent relationships through their individual attachment system, the teachers in the present study showed professional educational attitudes, characterized by a "reflective functioning" capacity (Slade, 2005); this may have prompted them to perceive the teacher-student relationship through a more objective exploratory lens rather than through their general attachment predispositions.

Consistent with $H 2$, the hierarchical regression analysis indicated that when introduced into the second step of the regression equation, student attachment security, overall teacher secure attachment style, and overall teacherreported security in the teacher-student relationship $(\beta=$ $0.24, \beta=0.31, \beta=0.35$ respectively) added a significant percentage (43\%) to the explained variance in the overall student appraisal of the teacher as a secure figure. These findings support the hypothesis that the students' care recipient perceptions of their day-to-day relationships with the teachers are affected by the attachment characteristics of their main caregivers. When introduced into the third step of the regression equation, the interaction between student attachment security and overall teacher secure attachment style $(\beta=0.36)$ contributed significantly (9\%) to the explanation of student appraisal of the teacher as a day-to-day secure figure. Additional analysis demonstrated a moderating role of the teacher's level of attachment security in the associations between the student's maternal attachment and student's appraisal of the teacher as a secure base. Studies on attachment have suggested that the correspondence between child-mother and child-teacher attachment security can be explained by the level of representation, meaning that secure attachment relational models that the child internalized in the course of maternal relationships are generalized to the relationships with teachers, guiding the child's subsequent behavior toward the teachers as an alternative secure base (Sabol \& Pianta, 2012). In the present study we found that these generalization mechanisms are operational only when the teacher's own level of security is adequate. The lack of association between maternal- and teacher attachmentsecurity within the group of children who had teachers with mid-low level of security suggests that the generalization of the relational models from mother-child to teacher-student relationships is contingent upon the attachment characteristics of the teacher. These findings are consistent with (and analogous to) those regarding the effect of the therapist's characteristics on counseling and therapy. For example, a study by Kim, Wampold, and Bolt (2006) showed a significant contribution of the therapist's characteristics on the outcomes of the psychotherapy process. The findings of the present study also strengthen Hughes's (2012) conceptualization that the quality of teacher-student relationships is determined significantly by the features that the teacher brings to the interactions. In other words, we suggest that in middle childhood as well as in early adolescence, the role of teachers in the normative educational systems educating students with disabilities is not limited to teaching academic knowledge but also involves aspects that are therapeutic in nature.

\subsection{Study Limitations}

The findings are based on concurrent associations; therefore the direction of the effects remains unclear. The concurrent associations may be related to a third factor, such as the teacher's age or the student's temperament or IQ level, which may affect the teacher-student relationship. The literature also indicates that the students' prior behavior problems and social abilities are related to the teacher-student relationship, raising further concerns about a third-variable bias. Therefore the present study should be supplemented by others examining similar research questions in a longitudinal design and controlling for prior assessments of each of the outcomes. Future research should also incorporate additional data sources, such as peer evaluation of ad hoc attachment relationships. Despite the above limitations, Sabol and Pianta (2012) noted that from a research point of view, it is problematic to assess the effect of the quality of early maternal attachment relationship behaviors on the quality of attachment relationship in middle childhood and early adolescence because of the dissimilarities in the measurement methods, which in middle childhood and early adolescence are commonly based on the children's perception of the relationships. Therefore, the concurrent examination, in the present study, of the relations between the students' maternal attachment, teacher attachment, and student-teacher attachment-like relationship quality have a practical value.

\subsection{Study Implications and Conclusions}

The present study contributes to a growing body of research highlighting the importance of understanding the quality of relationships of teachers with students at risk, and of developing educational counseling programs based on teacher-student relationship representations (Pianta, 1999, 2006). Howes and Hamilton (1992) showed that whereas nursery school training frequently includes emotional and social aspects as well as cognitive ones, school teacher training focuses virtually exclusively on educational aspects, ignoring other psycho-social developmental needs of students. Our findings draw attention to the need for developing a comprehensive approach for training school teachers to address the therapeutic-like aspects of their relationships with students with disabilities. The findings of the present study confirm Pianta's (1999) suggestion, according to which intervention, rather than beginning by modifying the teacher's behavior, should initially focus on teachers' representations of their close relationships with students through a consultation intervention designed to increase reflective qualities. For example, Spilt, Koomen, Thijs, and Van der Leij (2012) developed a teacher intervention based on individual counseling sessions that include the use of the Teacher Relationship Interview (TRI; Pianta, 1999), in order to bring out the teachers' relational models vis-à-vis their relationships with specific students. Furthermore, consultants helped the teachers associate the described representation with their day-to-day interactions with children, forming exclusive relational profiles that reflect strengths and weaknesses in the areas of sensitivity, secure base, perspective taking, negative and positive affect, etc. Subsequently, consultant-teacher sessions focused on using the teacher-student narrative profile of 
relationships to improve these relationships. According to the findings of Spilt, Koomen, Thijs, and Van der Leij (2012), teachers in general benefitted from the intervention program by achieving greater closeness and sensitivity, and fewer conflicts in their relationships. In conclusion, the findings of the present study contribute to better understanding the therapeutic-like aspects of the relationship between teachers and students with disabilities, and to knowledge about the attachment-like quality of this relationship.

\section{References}

[1] Alon-Reshef, A. (1994). Program for application of special education law. Jerusalem: Israeli Ministry of Education.

[2] Al-Yagon, M. (2009). Comorbid LD and ADHD in childhood: Socioemotional and behavioral adjustment and parent's positive and negative affect. European Journal of Special Education, 24(4), 371-391.

[3] Al-Yagon, M., \& Margalit, M. (2006). Loneliness, sense of coherence and perception of teachers as a secure base among children with reading difficulties. European Journal of Special Education, 21(1), 21-37.

[4] Al-Yagon, M., \& Mikulincer, M. (2004). Socioemotional and academic adjustment among children with learning disorders: The meditational role of attachment-based factors. Journal of Special Education, 38(2), 111-123.

[5] Al-Yagon, M., \& Mikulincer, M. (2006). Children's appraisal of teacher as a secure base and their socio-emotional and academic adjustment in middle childhood. Research in Education, 75, 1-18.

[6] American Psychiatric Association. (2000). Diagnostic and Statistical Manual of Mental Disorders ( $4^{\text {th }}$ ed., text revision). Washington DC: Author.

[7] Arthur, A. R. (2003). The emotional lives of people with learning disability. British Journal of Learning Disabilities, 31, 25-30.

[8] Atikem, L. S., \& West, S. G. (1991). Multiple regression: Testing and interpreting interactions. California: Sage.

[9] Baron, R., \& Kenny, D. (1986). The moderator-mediator variable distinction in social psychological research: Conceptual, strategic, and statistical considerations. Personality and Social Psychology, 51, 1173-1182.

[10] Bergin C., \& Bergin D. (2009). Attachment in the classroom. Educational Psychology Review, 21, 141-170.

[11] Birch, S. H., \& Ladd, G. W. (1997). The teacher-child relationship and children's early school adjustment. Journal of School Psychology, 35, 61-80.

[12] Buyse, E., Verschueren, K., \& Doumen, S. (2011). Preschoolers' attachment to mother and risk for adjustment problems in kindergarten: Can teachers make a difference? Social Development, 20, 33-50.

[13] Conners, C. K., Casat, C. D., Gualtieri, T., \& al,. (1996). Bupropion hydrochloride in attention deficit disorder with hyperactivity. Journal of the American Academy of Child \& Adolescent Psychiatry, 35, 1314-1321.

[14] Cotterell, J. L. (1992). The relation of attachment and supports to adolescent-well-being and school adjustment. Journal of Adolescent Research, 7, 28-42.

[15] Davis, H. A. (2003). Conceptualizing the role and influence of student-teacher relationships on children's social and cognitive development. Educational Psychologist, 38(4), 207-234.

[16] Hamre, B.K., \& Pianta, R. C. (2001). Early teacher-child relationships and the trajectory of children's school outcomes through eighth grade. Child Development, 72, 625-638.

[17] Harter, S. (1982). The perceived competence scale for children. Child Development, 53, 87-97.

[18] Hazan, C., \& Shaver, P. (1987). Romantic love conceptualized as an attachment process. Journal of Personality and Social Psychology, 52, 511-524.

[19] Howes, C., \& Hamilton, C. E. (1992). Children's relationships with caregivers: Mothers and child care teachers. Child Development, 63, 856-866.

[20] Hughes, J. N. (2012). Teacher-student relationships and school adjustment: Progress and remaining challenges. Attachment \& Human Development, 14(3), 319-327.
[21] Hughes, J. N., Gleason, K. A., \& Zhang, D. (2005). Relationship influence on teachers' perceptions of academic competence in academically at-risk minority and majority first grade classrooms. Journal of School Psychology, 43, 303-320.

[22] Israeli Ministry of Education General Manager Policy Circular (1994). The homeroom teacher. "Hozer Mankal" Ministry of Education general manager policy circular No 6 -October: http://www.education.org.il./Mankal (10-14) (Hebrew).

[23] Kernes, K. A., Klepac, L., \& Cole, A. (1996). Peer relationships and preadolescents' perceptions of security in the child-mother relationship. Developmental Psychology, 32, 457-466.

[24] Kesner, J. E. (2000). Teachers' characteristics and the quality of child-teacher relationships. Journal of School Psychology, 28(2), 133-149.

[25] Kim, D. M., Wampold, B. E., \& Bolt, D. M. (2006). Therapist effects in psychotherapy: A random-effects modeling of the national institute of mental health treatment of depression collaborative research program data. Psychotherapy Research, 16(2), 161-172.

[26] Koppitz, E. M. (1975). The Bender-Gestalt Test for young children: Research and application, 1963-1973. Orlando: Grune \& Stratton.

[27] Lynch, M., \& Cicchetti, D. (1992). Maltreated children's reports of relatedness to their teachers. In R. C. Pianta (Ed.), New directions in child development. Vol. 57: Relationships between children and non-parental adults (pp. 81-108). San Francisco: Josey-Bass.

[28] Mikulincer, M., \& Erev, I. (1991). Attachment style and the structure of romantic love. British Journal of Social Psychology, $30,273-291$.

[29] Mikulincer, M., \& Orbach, I. (1995). Attachment style and repressive defensiveness: The accessibility and architecture of affective memories. Journal of Personality and Social Psychology, 68(5), 917-925.

[30] Murray, C., \& Greenberg, M. T. (2006). Examining the importance of social relationships and social contexts in the lives of children with high-incidence disabilities. The Journal of Special Education, 39(4), 220-233.

[31] Murray, C., \& Murray, K. M. (2004). Child level correlates of teacher-student relationships: An examination of demographic characteristics, academic orientations and behavioral orientations. Psychology in the Schools, 41, 751-762.

[32] Murray, C., \& Pianta, R. C. (2007). The importance of teacherchild relationships for adolescents with high incidence disabilities. Theory into Practice, 46, 105-112.

[33] Myers, S. S., \& Pianta, R. C> (2008). Developmental commentary: Individual and contextual influences on student-teacher relationships and children's early problem behaviors. Journal of Clinical Child \& Adolescent Psychology, 37, 600-608.

[34] National Research Council and the Institute for Medicine. (2004). Engaging schools: Fostering high school students' motivation to learn. Washington, DC: National Academies Press.

[35] Oppenheim, D., Sagi, A., \& Lamb, M. (1988). Infant attachment at the kibbutz and their relation to social-emotional development four years later. Developmental Psychology, 24, 427-434.

[36] Osterrieth, P. (1946). Le test de copie d'une figure complex. Les Archives de Psychologie, 31, 206-356.

[37] Pianta, R. C., (1999). Supporting teachers: The key to affecting child-teacher relationships. In R. C. Pianta (Ed.), Enhancing relationships between children and teachers (pp. 125-168). Washington, DC: American Psychological Association.

[38] Pianta, R. C. (Ed.) (1996). Manual and scoring guide for the Student-Teacher Relationships Scale. Charlottesville: University of Virginia.

[39] Pianta, R. C. (2006). Classroom management and relationships between children and teachers: Implications for research and practice. In N. M. Evertson and C. S. Weinstein (Eds.), Handbook of classroom management: Research, practice, and contemporary issues (pp. 149-162). Mahwah, NJ: Lawrence Erlbaum Associates.

[40] Pianta, R. C., Nimetz, S. L., \& Bennet, E. (1997). Mother-child relationships, teacher-child relationships and adjustment in preschool and kindergarten. Early Childhood Research Quarterly, 12, 263-280.

[41] Pianta, R. C., \& Steinberg, M. S. (1992). Teacher-child relationships and the process of adjusting to school. New Directions for Child Development, 57, 61-80. 
[42] Sabol, T. J., \& Pianta, R. (2012). Recent trends in research on teacher-child relationships. Attachment \& Human Development, 14(3), 213-231.

[43] Spilt, J. L., Koomen, H. M. Y., \& van der Leij, A. (2012). Supporting teacher's relationships with disruptive children: The potential of relationships-focused reflection. Attachment \& Human Development, 14(3), 305-318.

[44] Saft, E. W., \& Pianta, R. C. (2001). Teachers' perceptions of their relationships with students: Effects of child age, gender, and ethnicity of teachers and children. School Psychology Quarterly, $16,125-141$

[45] Salomon, G., \& Mayseless, O. (2003). Dialectic contradictions in the experiences of Israeli Jewish adolescents: Efficacy and stress, closeness and friction, and conformity and non-compliance. In F. Pajares \& T. Urdan, (Eds.) Adolescence and Education, Volume III: International perspectives on adolescence (pp. 149-171). Greenwich, CT: Information Age Publishing.

[46] Schuengel, C. (2012). Teacher-child relationships as a developmental issue. Attachment \& Human Development, 14(3), 329-336.
[47] Slade, A. (2005). Parental reflective functioning: An introduction. Attachment and Human Development, 7, 261-281.

[48] Statistical Abstract of Israel-CBS (2012). Students with specia needs in primary education, by type of disability and type of setting, Statistical annual of Israel, 8.14

[49] Vakil, E., \& Blachstein, H. (1993). Rey Auditory-Verbal Learning Test: Structure analysis. Journal of Clinical Psychology, 49, 883890.

[50] Verschuren, K., \& Koomen, H. M. Y. (2012). Teacher-child relationships from an attachment perspective. Attachment \& Human Development, 14(3), 205-211.

[51] Wechsler, D. C. (1991). Wechsler Intelligence Scale for Children. (3d ed.). San Antonio, TX: Psychological Crop.

[52] Yair, G. (1991). The deprivation index: Paradoxes and empirical assessment, policy implications. Megamot, 34, 5-26 (Hebrew).

[53] Zionts, L. T. (2005). Examining relationships between students and teachers: A potential extension of attachment theory? In K. A. Kerns and R. A. Richardson (Eds.), Attachment in middle childhood (pp. 231-254). London: Guilford. 